\title{
Immunotherapy: Pancreatic Cancer and Extrahepatic Biliary Tract Cancer
}

\author{
Lukas Perkhofer Alica K. Beutel Thomas J. Ettrich \\ Klinik für Innere Medizin I, Universitätsklinikum UIm, Ulm, Germany
}

Keywords

Biliary tract cancer - Cancer - Checkpoint inhibition .

Cholangiocarcinoma $\cdot$ Immunotherapy $\cdot$ Pancreatic ductal adenocarcinoma

\section{Abstract}

Pancreatic ductal adenocarcinoma (PDAC) and extrahepatic biliary tract cancer (BTC) are among the malignancies with the highest morbidity and mortality. Despite increasing knowledge on biology and novel therapies, outcome remains poor in these patients. Recent progress in immunotherapies created new hopes in the treatment of PDAC and extrahepatic BTC. Several trials tested immunotherapies in various therapeutic situations as monotherapies or in combinations. Although responses were seen in some of the trials, the value of immunotherapy in PDAC and extrahepatic BTC remains unclear in the current situation, especially regarding the complex biological characteristics with a high stroma component, intrinsic resistance mechanisms and an immunosuppressive, hypoxic microenvironment. These major hurdles have to be taken into account and overcome if immunotherapies should be successful in these tumor entities. Thereby, combinational approaches that allow on the one hand targeted therapy and on the other restore or boost the function of immune cells are promising.

\section{Introduction}

Pancreatic ductal adenocarcinoma (PDAC) is one of the most lethal malignancies with a devastating 5-year survival rate of approximately $8 \%$ for all stages combined

[1]. At early stages, pancreatic cancer is usually asymptomatic whereas at advanced stages presenting symptoms may include jaundice, abdominal pain, weight loss, steatorrhea and new-onset diabetes. Due to its silent nature in early stages, PDAC is often diagnosed at an advanced or metastatic stage.

Surgical resection at best in combination with adjuvant systemic chemotherapy is the only potentially curative treatment, but less than $20 \%$ of patients are eligible for surgery with curative intent at the time of primary diagnosis. A recently published randomized phase III trial(PRODIGE 24) showed a significant survival benefit from adjuvant modified FOLFIRINOX (mFOLFIRINOX: 5-fluorouracil [FU]/leucovorin/irinotecan/oxaliplatin) compared to standard of care therapy with gemcitabine. The overall survival rate at 3 years was $63.4 \%$ in the mFOLFIRINOX group compared to $48.6 \%$ in the gemcitabine group, however at the expense of a higher toxicity [2]. However, not all patients can receive adjuvant treatment due to postoperative morbidity or prolonged convalescence. The strategy of adjuvant chemotherapy following surgery is currently challenged by several ongoing clinical trials of neoadjuvant or perioperative chemotherapy concepts in patients with borderline resectable tumors in order to increase the $\mathrm{R} 0$ resection rate and consecutively the survival rate. Gemcitabine has been the standard of care for locally advanced or metastatic PDAC patients since 1997. However, over the last few years the therapeutic landscape developed with implementation of two efficacious regimens in the management of advanced PDAC. The results from the MPACT trial demonstrated an improvement in median overall survival from 7 to 8.5 months for the combination of gemcitabine and nab-paclitaxel when compared to gemcitabine alone [3]. The results of the PRODIGE 4/ 
Table 1. Results from clinical trials with checkpoint inhibitors in pancreatic cancer and extrahepatic biliary tract cancer

\begin{tabular}{|c|c|c|c|c|c|}
\hline Molecule & Regimen & Phase & Patient population & Results & Reference \\
\hline \multirow[t]{2}{*}{$\begin{array}{l}\text { Ipilimumab } \\
\text { (anti-CTLA-4) }\end{array}$} & Monotherapy & II & $\begin{array}{l}\text { Locally advanced or metastatic } \\
\text { PDAC, } n=27\end{array}$ & $\begin{array}{l}\text { No objective response } \\
\text { (1 delayed response after } \\
\text { initial progression) }\end{array}$ & Royal et al. [18] \\
\hline & Combination with gemcitabine & $\mathrm{Ib}$ & Advanced PDAC, $n=16$ & $2 \mathrm{PR}, 5 \mathrm{SD}$ & Kalyan et al. [20] \\
\hline $\begin{array}{l}\text { Tremelimumab } \\
\text { (anti-CTLA-4) }\end{array}$ & Combination with gemcitabine & I & Metastatic PDAC, $n=34$ & $2 \mathrm{PR}$ & Aglietta et al. [19] \\
\hline \multirow[t]{2}{*}{$\begin{array}{l}\text { BMS-936559 } \\
\text { (anti-PD-L1) }\end{array}$} & Monotherapy & I & $\begin{array}{l}\text { Multiple entities, advanced or } \\
\text { metastatic PDAC, } n=14\end{array}$ & No objective response & Brahmer et al. [23] \\
\hline & Combination with chemotherapy & $\mathrm{Ib} / \mathrm{II}$ & $\begin{array}{l}\text { Multiple entities, metastatic } \\
\text { PDAC, } n=11\end{array}$ & $3 \mathrm{PR}, 8 \mathrm{SD}$ & Wiess et al. [25] \\
\hline $\begin{array}{l}\text { Nivolumab } \\
\text { (anti-PD-1) }\end{array}$ & $\begin{array}{l}\text { Combination with nab-paclitaxel } \pm \\
\text { gemcitabine }\end{array}$ & I & $\begin{array}{l}\text { Locally advanced or metastatic } \\
\text { PDAC, } n=17\end{array}$ & $5 \mathrm{PR}, 7 \mathrm{SD}$ & Wainberg et al. [26] \\
\hline
\end{tabular}

CTLA-4, cytotoxic T lymphocyte-associated protein 4; PDAC, pancreatic ductal adenocarcinoma; PR, partial remission; SD, stable disease; PD-L1, programmed cell death ligand-1; PD-1, programmed cell death-1.

ACCORD 11 have proven the FOLFIRINOX regimen to be superior to gemcitabine alone with an extended median overall survival of 11.1 months, however with an increased toxicity [4]. Results from the NAPOLI-1 trial have recently shown that nanoliposomal irinotecan in combination with 5-FU and leucovorin extends survival in patients with metastatic PDAC (mPDAC) who had previously received gemcitabine-based therapy. Another option for secondline therapy is a combination of oxaliplatin with 5-FU/folinic acid (OFF) as the phase III trial CONKO-003 has demonstrated [5]. For the first time, sequential treatment algorithms are proposed based on available data for patients with mPDAC. However, despite the advances in systemic cytotoxic chemotherapy strategies, the overall survival benefit is modest, and the prognosis of mPDAC still remains dismal. An even worse situation regarding limited evidence-based systemic treatment options is found in advanced extrahepatic biliary tract cancer (BTC) with platin (cisplatin, oxaliplatin)/gemcitabine as being the only standard of care therapy $[6,7]$.

PDAC and extrahepatic BTC are associated with high morbidity and mortality, and there is an urgent need for novel treatment options besides chemotherapy to improve survival outcomes and quality of life. An innovative treatment modality is immunotherapy which aims at augmenting the body's own immune system to fight cancer cells. Cancer immunotherapy has experienced a breakthrough in various cancer types and revolutionized traditional cancer treatment in various entities. The rapidly growing field of immunotherapies includes immune checkpoint blockade therapies, cancer vaccinations and chimeric antigen receptor (CAR) T-cell therapies. This review aims to provide an overview on the current state of immunotherapies in PDAC and extrahepatic BTC and to give an outlook on future directions.

\section{Checkpoint Inhibition as a New Therapeutic Strategy}

The immune system has the ability to recognize and eliminate cancer cells [8]. CD8+ cytotoxic T cells identify tumor-specific antigens that are presented by the major histocompatibility complex (MHC) class I molecule expressed on antigen-presenting cells through their $\mathrm{T}$-cell receptor.

Immune checkpoints are pathways that regulate the duration and amplitude of immune responses in physiological conditions in order to maintain self-tolerance and prevent autoimmunity [9]. Utilization of these pathways is an important mechanism of immune evasion of cancer cells. Tumor cells exploit immune checkpoints to avoid recognition and elimination by the immune system. The immune checkpoints that have been intensively studied are mainly cytotoxic $\mathrm{T}$ lymphocyte-associated protein 4 (CTLA-4) and programmed cell death-1 (PD-1) (Table 1). CTLA-4 and PD-1 are co-inhibitory receptors expressed on the surface of $\mathrm{T}$ cells that function as negative regulators of T-cell activation. Monoclonal antibodies targeting these immune checkpoint regulators can enhance endogenous antitumoral activity. So far, inhibition of immune checkpoints has been shown to be particularly effective in several malignancies such as melanoma [10], non-small cell lung cancer [11], urothelial carcinoma [12], renal-cell carcinoma [13], head and neck cancer [14] and hepatic cancer [15].

\section{Inhibition of the CTLA-4 Pathway}

CTLA-4 is a co-inhibitory receptor, whereas CD28 is a co-stimulatory receptor expressed on activated CD4+ and CD8+ T cells. CTLA- 4 and CD28 compete in binding the 
ligands B7-1 (also known as CD80) or B7-2 (also known as CD86) on antigen-presenting cells. CTLA-4 attenuates the activity of $\mathrm{T}$ cells by outcompeting CD28 in binding CD80 and CD86 and delivering inhibitory signals to the $\mathrm{T}$ cell $[9,16]$. Blockade of CTLA-4 has been shown to induce antitumoral activity [17]. Ipilimumab, a fully humanized IgG1 monoclonal antibody, blocks the ligand-receptor interaction of B7-1/B7-2 and CTLA-4. In 2010 ipilimumab was tested in a phase II trial in patients with advanced PDAC suggesting that single-agent ipilimumab does not demonstrate significant activity in the treatment of advanced PDAC [18]. A phase I dose escalation trial of tremelimumab, a fully humanized IgG2 monoclonal antibody antagonizing CTLA-4, demonstrated a safe profile when combined with gemcitabine in chemotherapy-naïve patients with metastatic PDAC [19]. A phase Ib trial of ipilimumab in combination with gemcitabine in advanced pancreatic cancer confirmed tolerability. However, the objective response rate did not seem to be significantly improved over gemcitabine alone in both trials [20].

\section{The PD-1/PD-L1 Pathway}

PD-1 is a co-inhibitory receptor expressed on T cells, $B$ cells, monocytes and natural killer T cells [21]. PD-1 has two ligands (PD-L1 and PD-L2) that are expressed on antigen-presenting cells. Binding of PD-L1 or PD-L2 to PD-1 downregulates the expression of anti-apoptotic molecules and attenuates T cell activation [22]. AntiPD-1 inhibitors block the interaction with PD-L1 and PD-L2 resulting in decreased tumor growth.

In a phase I clinical trial of anti-PD-L1 (BMS-936559) therapy in advanced pretreated solid tumors, no antitumor activity was seen in the 14 PDAC patients included. Other solid tumors like melanoma, lung cancer and renal-cell cancer did however show significant tumor regression [23]. Preclinical data from murine transplant models showed an antitumoral effect for PD-1 or PD-L1 blockade combined with chemotherapy [24]. A phase Ib trial evaluated pembrolizumab, a humanized IgG4 monoclonal antibody against PD-1, combined with various chemotherapies across multiple advanced solid tumors. In total 11 patients with metastatic PDAC (after first-line chemotherapy or treatment naïve) received chemotherapy in combination with pembrolizumab. Two patients showed a partial remission, 6 patients had a stable disease [25]. Interim results from a phase I trial combining nivolumab plus nab-paclitaxel with or without gemcitabine showed a response in 12 out of 17 patients ( 5 patients partial remission, 7 patients stable disease) with locally advanced or metastatic PDAC [26]. These results appear promising but larger clinical trials are needed to evaluate any statistically significant clinical benefit.
Regarding biliary tract cancer, encouraging results have recently been published. Thirty-four patients who had progressed on at least one line of systemic therapy received nivolumab. Out of 29 evaluable patients, 5 patients achieved partial remission and 11 patients achieved stable disease [27]. Phase II trials with mono or dual checkpoint inhibition or combined with gemcitabine/cisplatin are currently recruiting (e.g. NCT03101566, NCT02829918).

\section{Immunogenic Subtypes of PDAC and Extrahepatic BTC}

A small subset of PDAC patients with mismatch repair deficiency (MMR) showed significant clinical benefit with immune checkpoint inhibitors. In a phase II study conducted by Le and Durham [28], 86 patients with MMR-deficient advanced tumors of 12 different tumor types demonstrated efficiency with anti-PD-1 therapy. Eight patients with PDAC were included in the study and achieved an objective response rate of $62 \%$. The mismatch repair system corrects DNA damage introduced into microsatellites (short tandemly repeated sequences) during replication to maintain genomic stability [29]. Defects in the MMR system or loss of function of MMR proteins (MLH1, MSH2, MSH6, PMS2) lead to an accumulation of mutations in microsatellites, resulting in a microsatellite instable (MSI) phenotype [30]. Unfortunately, MSI is a rare event that only occurs in about $1 \%$ of all PDAC tumors and in about $5-13 \%$ of extrahepatic BTC [31-33]. However, National Comprehensive Cancer Network guidelines encourage to consider MSI and/or MMR testing on tumor tissue for patients with locally advanced or metastatic PDAC [34].

Generally tumor immunogenicity is caused by the degree of structural epitope differences compared to normal cells that allows $\mathrm{T}$ cell recognition and interference [35]. A defective DNA repair system increases the tumor mutational burden (TMB) resulting in a higher neoantigen load. Thereby the increased neoantigen expression further sensitizes to immune checkpoint blockade irrespective of the tumor type. High TMB is positively correlated with response to checkpoint inhibition across diverse tumor entities [36, 37]. But compared to other solid tumors PDAC has a low TMB with a median number of about 1 somatic mutation per megabase as opposed to solid tumors with a high mutational load of about 10 somatic mutations per megabase (melanoma, lung cancer, bladder cancer) [38]. Tumor-infiltrating lymphocytes (TILs) are crucial in the complex immunogenic response and increased in high TMB [39]. But within the pronounced desmoplastic stromal compartment TILs are rare and classify PDAC more or less as noninflamed [40, 41]. Im-
30

Visc Med 2019;35:28-37 DOI: 10.1159/000497291
Perkhofer/Beutel/Ettrich 
munosuppressive cells like $\mathrm{T}$ regulatory cells or myeloid cells are frequently found in the stroma and are contradictory to TILs [42]. Additionally, the stroma-related hypoxic tumor microenvironment favors these non-TIL cells in response to activated cancer-associated fibroblasts [43-45]. In sum, the previously mentioned factors contribute to the immunosuppressive tumor microenvironement that enables a therapy resistance mechanism as a possible explanation for the unresponsiveness to checkpoint inhibition. As a consequence, pro-immunogenic strategies are needed in PDAC, as far as various tumorassociated antigens (TAAs) are known. Similar conditions are found in extrahepatic biliary tract cancer. Single agent immune checkpoint inhibitors have only very limited efficiency in both cancer entities unless the tumor is microsatellite instable and so there is a need for combination strategies.

\section{Adoptive T-Cell Therapy}

CAR T-cell therapy is a form of immunotherapy that redirects patients' $T$ cells to specifically target and destroy tumor cells. Adoptive T-cell therapy has demonstrated impressive results in hematological B cell malignancies like B cell lymphoma [46-49] and acute lymphoblastic leukemia $[46,50]$.

As a first step in the manufacturing process, T cells are isolated from peripheral blood of the patient by means of leukapheresis. Ex vivo $\mathrm{T}$ cells are activated and virally transducted with the vector encoding the CAR, an artificial $\mathrm{T}$ cell receptor. CAR T cells are further extended and reinfused into the patient. CAR $\mathrm{T}$ cells recognize tumor surface antigens independently from MHC restriction and kill tumor cells upon antigen contact.

Multiple early phase I studies demonstrate efficacy in CAR T-cell therapy in preclinical models of pancreatic cancer. Targeting against the tumor antigen mesothelin [51, 52], carcinoembryonic antigen [53], prostate stem cell antigen [54, 55], HER2 neu, CD24 [56], CD133 and mucin-1 (MUC-1) [57] has shown activity in preclinical tumor models. Currently, multiple clinical phase I and II trials using CAR T-cell therapy targeting prostate stem cell antigen (e.g. NCT02744287) are ongoing.

CAR T-cell therapy has made tremendous successes in hematological malignancies, its application in PDAC and extrahepatic BTC is still at the beginning.

\section{Vaccination Strategies in PDAC and Extrahepatic BTC}

A key characteristic of PDAC is its low immunogenicity that is driven by various means. As mentioned before, TMB is low in PDAC and extrahepatic BTC with only rarely expressed neoantigens, limiting the response to immunotherapies [37, 38]. Pro-immunogenic strategies are warranted to overcome this hurdle as far as various TAAs are known for both cancers, especially the highly immunogenic neoantigens driven by KRAS mutations in PDAC [58]. Particularly immune modulation via vaccination strategies seems to be promising in both cancer types. Thereby, vaccine immunotherapy in cancer treatment aims to activate an immune response by achieving TAA presentation. Therefore, different concepts exist including whole-cell, dendritic-cell (DC), DNA and peptide vaccines.

\section{Peptide and Protein-Based Vaccines}

Various TAAs are described in PDAC and BTC that can be targeted, like mucin 5AC [59], C-ERC/mesothelin [60, 61], mutS homolog 2 (MSH2), postmeiotic segregation increased 1 (PMS1) [62], cancer-testis antigens [63] and Forkhead box M1 [64]. In line a phase I study obtained first interventional steps with an autologous vaccine HSPPC-96 (heat shock protein gp96) purified from completely resected PDACs. In total 10 patients received each 4 doses of autologous HSPPC-96. Safety was proved, and no correlation between immune response and prognosis could be seen [65].

KRAS has been in the focus as the key TAA knowing that in up to $90 \%$ of PDAC KRAS point mutations are found (most frequent KRAS ${ }^{\mathrm{G} 12 \mathrm{D}}$ ) that can allow cytotoxic T cell recognition [66-69]. Initial trials with RAS vaccines could verify safety and showed a transient $\mathrm{T}$ cell PDAC response [70]. Following that, two phase II clinical trials used subcutaneous KRAS vaccination combined with GM-CSF in the adjuvant setting [71, 72]. In total 23 patients were treated, 10 patients with a single peptide vaccine that corresponded to the KRAS mutation of the cancer and 13 patients with a mixture of the 7 most common mutated RAS peptides in PDAC. Vaccination was well tolerated, and survival times after 10 years were $20 \%$ (4/20 evaluable patients) compared to $0 \%(0 / 87)$ in a cohort of nonvaccinated patients treated in the same period $[71,72]$. Similar results were achieved in another adjuvant use of a RAS peptide vaccine in 5 PDAC patients with a mean overall survival (OS) time of 44.4 months [23]. Finally Abou-Alfa et al. [73] vaccinated 24 resected PDAC patients harboring a KRAS ${ }^{\mathrm{G} 12 \mathrm{D}}$ mutation with a 21-mer peptide vaccine containing the KRAS mutation of the patient's tumor. The therapy was well tolerated, and 9 patients were evaluable for immune response. The median OS time in this study was 20.3 months. Currently under investigation is the combination of the RAS vaccine TG01 (a mixture of 7 RAS peptides)/GM-CSF with gemcitabine versus gemcitabine monotherapy as an adjuvant treatment in resected (R0 or R1) RAS-mutant PDAC patients (NCT02261714). A first interim analysis 
of 19 patients showed promising results with a 2-year OS rate of $68.4 \%$ and a median OS of 33.1 months [74]. However, these promising results in the adjuvant setting could not directly be transferred to the palliative setting when used as monotherapies. Gjertsen et al. [70] treated 38 patients with advanced PDAC and showed a significant survival benefit that depends on the immune response (median OS 148 days vs. 61 days in nonimmune responders; $p=0.0002$ ), when using a KRAS vaccine adjusted to the patients' mutation.

Carcinoembryonic antigen is another vaccination target of interest tested in PDAC. Although showing promising results in early phase clinical trials $[75,76]$, a randomized phase III trial with a carcinoembryonic antigentargeted vaccine in PDAC second-line therapy failed to show a survival benefit compared to palliative chemotherapy or best supportive care [77]. The high need for a tumor response and the complex microenvironment in advanced PDAC may be more suitable for combinational approaches. Considering that, we are looking forward to the data of further upcoming randomized trials, in combination with checkpoint inhibitors (e.g., NCT02472977, NCT02350673).

Another focus is set on the antigastrin-17 diphtheria toxin-coupled vaccine G17DT that acts against the growth factor gastrin-17. A first phase II study in 30 advanced PDAC patients confirmed a dose dependent significant survival benefit for antibody responders (217 days) versus nonresponders (121 days) [78]. The treatment of 154 chemotherapy-naïve patients with advanced PDAC with G17DT led to a nearly doubled median OS time (151 days) compared to the placebo group (82 days). Again, the survival benefit was significantly dependent on the antiG17DT response [79]. Negative results were reported by Shapiro et al. [80] in advanced PDAC treatment for the combination of gemcitabine plus G17DT (median OS 5.8 months) compared to gemcitabine plus placebo (median OS 6.6 months). The final results of a phase III trial in advanced PDAC patients treated with sequentially administered G17DT or placebo are pending (NCT02118077).

Increased telomerase expression in PDAC [81] is accompanied by the induction of human telomerase reverse transcriptase [82] and relevant for tumorigenesis. Therefore the human telomerase reverse transcriptase peptidebased vaccine GV1001 was developed. Despite promising phase I/II trial results, GV1001 failed to show a significant survival benefit for advanced PDAC patients in a phase III trial [83].

MUC-1 is a glycoprotein that has a function in cell signaling with oncogenic implications on cell polarity, motility and angiogenesis $[84,85]$. Overexpression is found in several tumors like PDAC [86] and BTC [87] and is linked to a highly immunogenic target [88] with implications on drug resistance [89]. In a phase I trial 6 PDAC and 3 BTC patients in a palliative setting were treated with a 100-mer MUC-1 peptide, resulting in mainly tumor progression after 7 weeks [90]. Similar disappointing results for peptide-based MUC-1 vaccines were obtained by Ramanathan et al. [91].

Furthermore, in BTC alternative epitopes and approaches can be found. Aruga et al. treated 9 (4 intrahepatic, 3 extrahepatic BTC and 1 gallbladder cancer) advanced chemotherapy refractory BTC patients with a three-peptide vaccine (cell division cycle-associated 1 , cadherin 3 and kinesin family member 20A). All patients had a peptide-specific $\mathrm{T}$ cell immune response, and stable disease was observed in 5 of 9 patients after 8 weeks of therapy. The median progression-free survival was 3.4 months and the median OS 9.7 months [92]. In another similar therapeutic situation 9 patients were treated with a four-peptide derived vaccine from cancer-testis antigens. Clinical responses were observed in 6 of 9 patients with a median OS of 380 days. The injection site reaction and cytotoxic $\mathrm{T}$ cell induction seemed to be prognostic factors for survival [93].

\section{Whole-Cell-Based Vaccines}

Whole-cell vaccines are normally derived from the primary tumor and express various epitopes of CD8+ and $\mathrm{CD} 4+\mathrm{T}$ cells. This advanced approach ensures to hit all potentially relevant antigens and allows multiple TAA targeting in parallel. However, only a small number of patients undergo surgery for PDAC, and the total number of tumor cells is often low; therefore, allogeneic cell lines are alternatively used [94-97]. The use of allogeneic tumor cells can further bypass the need of individualizing each therapy. The mixture of several cell lines from various tumors can improve the overlap of the antigens expressed and the patient's tumor. Moreover, preclinical models taught us that insufficient tumor defeat is mainly caused by the inability of the immune system to appropriately respond to TAAs [98]. Here, cytokines can assist by enabling an immunological boost, and GM-CSF was found to be a highly potent inducer [99], that can also be used therapeutically $[99,100]$.

GVAX pancreas is a lethally irradiated allogeneic whole-cell tumor vaccine that is genetically modified to secrete GM-CSF and in parallel deliver TAAs [99]. In the ECLIPSE phase IIb trial, advanced PDAC patients who had failed previous therapy were enrolled and treated with either GVAX pancreas plus mesothelin-expressing live-attenuated Listeria monocytogenes (CRS-207) as an immunogenic boost, or CRS-207 alone or physician's choice of single-agent chemotherapy. Upfront the patients received low-dose cyclophosphamide for inhibition of regulatory $\mathrm{T}$ cells in the GVAX combination arm, an effect confirmed in BTC [101]. With a median OS of 3.8 months GVAX plus CRS-207 was neither superior to 
the chemotherapy arm (4.6 months) nor the CRS-207 arm (5.4 months) [102].

Within another single-center phase II study, 60 curatively resected patients were treated with GVAX and subsequent 5 -FU-based chemoradiation. The therapy was well tolerated, the median OS was 24.8 months, and the disease-free survival correlated with the induction of a mesothelin-specific $\mathrm{T}$ cell response in the patients [103]. The aforementioned telomerase vaccine GV1001 failed to show a survival benefit in combination with gemcitabine (median OS 5.9 months) to gemcitabine (median OS 7.3 months) only in chemotherapy-naïve, advanced PDAC patients in a phase III trial [83]. However, as far as GVAX could not fulfill the expectation of a one-fits-all vaccine, alternative strategies are needed to boost the efficacy. Therefore combinations of GVAX with checkpoint inhibitors like nivolumab (NCT02243371, NCT03190265), pembrolizumab (NCT02648282) or ipilimumab (NCT03190265) are currently under investigation.

Another tested vaccine is algenpantucel- $\mathrm{L}$ consisting of allogeneic irradiated pancreatic cancer cells with expression of $\alpha$-1,3-galactosyl transferase, an enzyme catalyzing the synthesis of $\alpha$-galactosyl epitopes. The vaccine thereby aims to boost the activity against $\alpha$-galactosyllabeled tumor cells. Promising preclinical results [104, 105] paved the way for clinical trials. The IMPRESS phase III study included 722 resected PDAC patients who received adjuvant standard of care chemotherapy with or without radiation with algenpantucel-L. The study failed by showing a median OS of 27.3 months for the addition of algenpantucel-L compared to 30.4 months with standard of care alone [106].

\section{Dendritic Cell Vaccines}

DCs act as highly effective antigen-presenting cells that facilitate cytolytic and regulatory $\mathrm{T}$ cell reaction [107]. DCs can be manipulated in several ways in order to achieve an antitumor response [108].

Within a phase I trial DCs were pulsed with a mixture of three types of Wilms tumor 1 peptides (MHC I and/or II) and combined with gemcitabine as palliative treatment in advanced PDAC patients. In this trial the combination of both MHC class I- and II-restricted epitopes was linked to a delayed-type hypersensitivity (3/10 patients) that resulted in a significant survival benefit (median OS 717 days) compared to negative control [109]. In a previous phase I study, safety for the WT1 vaccine in combination with gemcitabine could also be confirmed for intrahepatic (4 patients) and extrahepatic (4 patients) BTC, although an objective clinical efficacy was missing with a disease control rate of $50 \%$ after 2 months of therapy [110].

As previously mentioned MUC-1 is a highly immunogenic target in PDAC but also BTC. Lepisto et al. [111] conducted an adjuvant phase I/II clinical trial of a MUC-
1 peptide-loaded DC vaccine in 10 resected $\mathrm{PDAC}$ and 2 BTC patients. After 4 years, 33\% (4/12) of the patients were still alive without evidence of a relapse [111]. Feasibility of the approach is confirmed in another 10 cancer patients treated with autologous DCs transfected with cDNA of MUC-1 by Pecher et al. [112].

A retrospective analysis of 65 advanced BTC patients that were treated with WT1 and/or MUC1 pulsed DCs verified the safety of the vaccination and showed a clinical response in patients who underwent additional chemotherapy (median OS with chemotherapy 8.2 months, without chemotherapy 5.3 months) [113].

\section{Discussion}

The recent immunotherapy progress in solid oncology created a hype and new hopes in various cancer entities. However, we had to learn that this could not be generalized, and tumor response is entity specific. Definitive positive results are published for MSI-high tumors and for tumors with a high mutational burden. Regarding this in MSI-high tumors checkpoint inhibitor therapy is FDA approved irrespective of the entity. The evolving field of checkpoint inhibition shows no clear benefit at the moment in phase I-II trials; anyhow, there are some responders. For now, the interpretation of the published data is hampered by low patient numbers, partially missing controls, varying therapy lines/previous therapies and inconsistent therapy regimen. Only few studies have used the state-of-the-art first-line therapies for advanced PDAC, e.g. with gemcitabine/nab-paclitaxel combined with nivolumab. The optimal time point for the use of a checkpoint inhibitor remains elusive. Anyhow combinational strategies of a checkpoint inhibitor with a chemotherapy backbone seem to be more promising in PDAC and extrahepatic BTC. Probably this is caused by the special biology with a high stroma component, intrinsic resistance mechanisms and an immunosuppressive and hypoxic microenvironment. PDACs are among the most immune cold cancers with a low mutational burden. Both are contradictory to the aforementioned criteria for response to checkpoint inhibitors. Moreover, there are no established biomarkers that predict therapy response in case of checkpoint inhibition in PDAC and extrahepatic BTC, but in some studies a high PD-L1 expression was associated with poor outcome [114].

Regarding all those tumor microenvironment-driven factors it is difficult to believe that immune checkpoint inhibitor monotherapy will be successful at least in PDAC. To overcome these hurdles alternative strategies are warranted that activate the immune response. A possible approach could be vaccination strategies. However, after first promising results GVAX as the most intensively studied 
vaccine failed in a phase III trial. This shows the need for a better stratification of the patients and the use of alternative combinational strategies as an example with immune checkpoint inhibitors or other immune modulators.

\section{Statement of Ethics}

The authors have no ethical conflicts to disclose.

\section{Disclosure Statement}

L.P. got travel grants from IPSEN Pharma and Novartis for national and international medical conferences. T.J.E. received travel grants from IPSEN outside the submitted work. He acted as con- sultant for Bayer, BMS, Sanofi, Merck Serono, Roche and Novartis outside the submitted work. He received lecture fees from Merck Serono, Sanofi and Celgene. One of his research projects is supported by Servier. A.K.B. has no possible conflicts of interest to declare.

\section{Funding Sources}

The authors have no funding sources to declare.

\section{Author Contributions}

A.K.B., T.J.E. and L.P. were responsible for conception, literature research, writing and drafting of the manuscript.

\section{References}

1 Siegel RL, Miller KD, Jemal A. Cancer Statistics, 2017. CA Cancer J Clin. 2017 Jan;67(1): 7-30.

2 Conroy T, Hammel P, Hebbar M, Ben Abdelghani M, Wei AC, Raoul JL, et al.; Canadian Cancer Trials Group and the Unicancer-GIPRODIGE Group. FOLFIRINOX or Gemcitabine as Adjuvant Therapy for Pancreatic Cancer. N Engl J Med. 2018 Dec;379(25): 2395-406.

3 Vogel A, Römmler-Zehrer J, Li JS, McGovern D, Romano A, Stahl M. Efficacy and safety profile of nab-paclitaxel plus gemcitabine in patients with metastatic pancreatic cancer treated to disease progression: a subanalysis from a phase 3 trial (MPACT). BMC Cancer. 2016 Oct;16(1):817.

4 Conroy T, Desseigne F, Ychou M, Bouché O, Guimbaud R, Bécouarn Y, et al.; Groupe Tumeurs Digestives of Unicancer; PRODIGE Intergroup. FOLFIRINOX versus gemcitabine for metastatic pancreatic cancer. N Engl J Med. 2011 May;364(19):1817-25.

5 Oettle H, Riess H, Stieler JM, Heil G, Schwaner I, Seraphin J, et al. Second-line oxaliplatin, folinic acid, and fluorouracil versus folinic acid and fluorouracil alone for gemcitabine-refractory pancreatic cancer: outcomes from the CONKO-003 trial. J Clin Oncol. 2014 Aug;32(23):2423-9.

6 Valle J, Wasan H, Palmer DH, Cunningham D, Anthoney A, Maraveyas A, et al.; ABC-02 Trial Investigators. Cisplatin plus gemcitabine versus gemcitabine for biliary tract cancer. N Engl J Med. 2010 Apr;362(14): 1273-81.

7 Malka D, Cervera P, Foulon S, Trarbach T, de la Fouchardière C, Boucher E, et al.; BINGO investigators. Gemcitabine and oxaliplatin with or without cetuximab in advanced biliary-tract cancer (BINGO): a randomised, open-label, non-comparative phase 2 trial. Lancet Oncol. 2014 Jul;15(8):819-28.

8 Swann JB, Smyth MJ. Immune surveillance of tumors. J Clin Invest. 2007 May;117(5):113746.

9 Pardoll DM. The blockade of immune checkpoints in cancer immunotherapy. Nat Rev Cancer. 2012 Mar;12(4):252-64.
10 Robert C, Long GV, Brady B, Dutriaux C, Maio M, Mortier L, et al. Nivolumab in previously untreated melanoma without BRAF mutation. N Engl J Med. 2015 Jan;372(4): 320-30.

11 Borghaei H, Paz-Ares L, Horn L, Spigel DR, Steins M, Ready NE, et al. Nivolumab versus Docetaxel in Advanced Nonsquamous NonSmall-Cell Lung Cancer. N Engl J Med. 2015 Oct;373(17):1627-39.

12 Sharma P, Retz M, Siefker-Radtke A, Baron A, Necchi A, Bedke J, et al. Nivolumab in metastatic urothelial carcinoma after platinum therapy (CheckMate 275): a multicentre, single-arm, phase 2 trial. Lancet Oncol. 2017 Mar;18(3):312-22.

13 Motzer RJ, Escudier B, McDermott DF, George S, Hammers HJ, Srinivas S, et al.; CheckMate 025 Investigators. Nivolumab versus Everolimus in Advanced Renal-Cell Carcinoma. N Engl J Med. 2015 Nov;373(19): 1803-13.

14 Ferris RL, Blumenschein G Jr, Fayette J, Guigay J, Colevas AD, Licitra L, et al. Nivolumab for Recurrent Squamous-Cell Carcinoma of the Head and Neck. N Engl J Med. 2016 Nov;375(19):1856-67.

15 El-Khoueiry AB, Sangro B, Yau T, Crocenzi TS, Kudo M, Hsu C, et al. Nivolumab in patients with advanced hepatocellular carcinoma (CheckMate 040): an open-label, noncomparative, phase $1 / 2$ dose escalation and expansion trial. Lancet. 2017 Jun;389(10088): 2492-502.

16 Rudd CE, Taylor A, Schneider H. CD28 and CTLA-4 coreceptor expression and signal transduction. Immunol Rev. 2009 May; 229(1):12-26.

17 Leach DR, Krummel MF, Allison JP. Enhancement of antitumor immunity by CTLA4 blockade. Science. 1996 Mar;271(5256): 1734-6.

18 Royal RE, Levy C, Turner K, Mathur A, Hughes M, Kammula US, et al. Phase 2 trial of single agent Ipilimumab (anti-CTLA-4) for locally advanced or metastatic pancreatic adenocarcinoma. J Immunother. 2010 Oct; 33(8):828-33
19 Aglietta M, Barone C, Sawyer MB, Moore MJ, Miller WH Jr, Bagalà C, et al. A phase I dose escalation trial of tremelimumab (CP$675,206)$ in combination with gemcitabine in chemotherapy-naive patients with metastatic pancreatic cancer. Ann Oncol. 2014 Sep; 25(9):1750-5.

20 Kalyan A, Kircher SM, Mohindra NA, Nimeiri HS, Maurer V, Rademaker A, et al. Ipilimumab and gemcitabine for advanced pancreas cancer: a phase Ib study. J Clin Oncol. 2016; 34 Suppl 15:e15747.

21 Yamazaki T, Akiba H, Iwai H, Matsuda $H$, Aoki M, Tanno Y, et al. Expression of programmed death 1 ligands by murine $\mathrm{T}$ cells and APC. J Immunol. 2002 Nov;169(10): 5538-45.

22 Keir ME, Butte MJ, Freeman GJ, Sharpe AH. PD-1 and its ligands in tolerance and immunity. Annu Rev Immunol. 2008;26(1):677704.

23 Brahmer JR, Tykodi SS, Chow LQ, Hwu WJ, Topalian SL, Hwu P, et al. Safety and activity of anti-PD-L1 antibody in patients with advanced cancer. N Engl J Med. 2012 Jun; 366(26):2455-65.

24 Nomi T, Sho M, Akahori T, Hamada K, Kubo A, Kanehiro H, et al. Clinical significance and therapeutic potential of the programmed death-1 ligand/programmed death-1 pathway in human pancreatic cancer. Clin Cancer Res. 2007 Apr;13(7):2151-7.

25 Weiss GJ, Waypa J, Blaydorn L, Coats J, McGahey K, Sangal A, et al. A phase Ib study of pembrolizumab plus chemotherapy in patients with advanced cancer (PembroPlus). $\mathrm{Br}$ J Cancer. 2017 Jun;117(1):33-40.

26 Wainberg ZA, Hochster HS, George B, Gutierrez M, Johns ME, Chiorean EG, et al. Phase I study of nivolumab (nivo) + nab-paclitaxel (nab-P) \pm gemcitabine (Gem) in solid tumors: interim results from the pancreatic cancer (PC) cohorts. J Clin Oncol. 2017;35 Suppl 4: 412.

27 Kim R, Kim D, Alese O, et al. O-009A phase II multi institutional study of nivolumab in patients with advanced refractory biliary tract cancers (BTC). Ann Oncol. 2018;29 Suppl 5:mdy149.008-mdy149.008. 
28 Le DT, Durham JN, et al. Mismatch repair deficiency predicts response of solid tumors to PD-1 blockade. Science. 2017;357:409-13. DOI: 10.1126/science.aan6733.

29 Boland CR, Goel A. Microsatellite instability in colorectal cancer. Gastroenterology. 2010 Jun;138(6):2073-2087.e3.

30 Zhang CM, Lv JF, Gong L, Yu LY, Chen XP, Zhou HH, et al. Role of Deficient Mismatch Repair in the Personalized Management of Colorectal Cancer. Int J Environ Res Public Health. 2016 Sep;13(9):13.

31 Humphris JL, Patch AM, Nones K, Bailey PJ, Johns AL, McKay S, et al.; Australian Pancreatic Cancer Genome Initiative. Hypermutation In Pancreatic Cancer. Gastroenterology. 2017 Jan;152(1):68-74.e2.

32 Suto T, Habano W, Sugai T, Uesugi N, Kanno $\mathrm{S}$, Saito $\mathrm{K}$, et al. Infrequent microsatellite instability in biliary tract cancer. J Surg Oncol. 2001 Feb;76(2):121-6.

33 Silva VW, Askan G, Daniel TD, Lowery M, Klimstra DS, Abou-Alfa GK, et al. Biliary carcinomas: pathology and the role of DNA mismatch repair deficiency. Linchuang Zhongliuxue Zazhi. 2016 Oct;5(5):62.

34 Guidelines NC. Version 1.2019 [cited 2019 Jan 6]. Available from: https://www.nccn.org/ professionals/physician_gls/pdf/pancreatic. pdf.

35 Chen DS, Mellman I. Oncology meets immunology: the cancer-immunity cycle. Immunity. 2013 Jul;39(1):1-10.

36 Goodman AM, Kato S, Bazhenova L, Patel SP, Frampton GM, Miller V, et al. Tumor Mutational Burden as an Independent Predictor of Response to Immunotherapy in Diverse Cancers. Mol Cancer Ther. 2017 Nov;16(11): 2598-608.

37 Brown SD, Warren RL, Gibb EA, Martin SD, Spinelli JJ, Nelson $\mathrm{BH}$, et al. Neo-antigens predicted by tumor genome meta-analysis correlate with increased patient survival. Genome Res. 2014 May;24(5):743-50.

38 Alexandrov LB, Nik-Zainal S, Wedge DC, Aparicio SA, Behjati S, Biankin AV, et al; Australian Pancreatic Cancer Genome Initiative; ICGC Breast Cancer Consortium; ICGC MMML-Seq Consortium; ICGC PedBrain. Signatures of mutational processes in human cancer. Nature. 2013 Aug;500(7463):415-21.

39 Mellman I, Coukos G, Dranoff G. Cancer immunotherapy comes of age. Nature. 2011 Dec; 480(7378):480-9.

40 Erkan M, Hausmann S, Michalski CW, Fingerle AA, Dobritz M, Kleeff J, et al. The role of stroma in pancreatic cancer: diagnostic and therapeutic implications. Nat Rev Gastroenterol Hepatol. 2012 Aug;9(8):454-67.

41 Neesse A, Bauer CA, Öhlund D, Lauth M, Buchholz M, Michl P, et al. Stromal biology and therapy in pancreatic cancer: ready for clinical translation? Gut. 2019 Jan;68(1):159-71.

42 Tsujikawa T, Kumar S, Borkar RN, Azimi V, Thibault G, Chang YH, et al. Quantitative Multiplex Immunohistochemistry Reveals Myeloid-Inflamed Tumor-Immune Complexity Associated with Poor Prognosis. Cell Reports. 2017 Apr;19(1):203-17.

43 Kalluri R. The biology and function of fibroblasts in cancer. Nat Rev Cancer. 2016 Aug; 16(9):582-98.
44 Mariathasan S, Turley SJ, Nickles D, Castiglioni A, Yuen K, Wang Y, et al. TGF $\beta$ attenuates tumour response to PD-L1 blockade by contributing to exclusion of T cells. Nature. 2018 Feb;554(7693):544-8.

45 Palazon A, Goldrath AW, Nizet V, Johnson RS. HIF transcription factors, inflammation, and immunity. Immunity. 2014 Oct;41(4): 518-28.

46 Schuster SJ, Svoboda J, Chong EA, Nasta SD, Mato AR, Anak Ö, et al. Chimeric Antigen Receptor T Cells in Refractory B-Cell Lymphomas. N Engl J Med. 2017 Dec;377(26): 2545-54.

47 Locke FL, Neelapu SS, Bartlett NL, Siddiqi T, Chavez JC, Hosing CM, et al. Phase 1 Results of ZUMA-1: A Multicenter Study of KTEC19 Anti-CD19 CAR T Cell Therapy in Refractory Aggressive Lymphoma. Mol Ther. 2017 Jan;25(1):285-95.

48 Kochenderfer JN, Dudley ME, Kassim SH, Somerville RP, Carpenter RO, Stetler-Stevenson $\mathrm{M}$, et al. Chemotherapy-refractory diffuse large B-cell lymphoma and indolent B-cell malignancies can be effectively treated with autologous $\mathrm{T}$ cells expressing an anti-CD19 chimeric antigen receptor. J Clin Oncol. 2015 Feb;33(6):540-9.

49 Neelapu SS, Locke FL, Bartlett NL, Lekakis LJ, Miklos DB, Jacobson CA, et al. Axicabtagene Ciloleucel CAR T-Cell Therapy in Refractory Large B-Cell Lymphoma. N Engl J Med. 2017 Dec;377(26):2531-44.

50 Maude SL, Frey N, Shaw PA, Aplenc R, Barrett DM, Bunin NJ, et al. Chimeric antigen receptor T cells for sustained remissions in leukemia. N Engl J Med. 2014 Oct;371(16):150717.

51 O’Hara M, Stashwick C, Haas AR, Tanyi JL. Mesothelin as a target for chimeric antigen receptor-modified $\mathrm{T}$ cells as anticancer therapy. Immunotherapy. 2016;8(4):449-60.

52 Chen Y, Ayaru L, Mathew S, Morris E, Pereira SP, Behboudi S. Expansion of anti-mesothelin specific CD4+ and CD8+ T cell responses in patients with pancreatic carcinoma. PLoS One. 2014 Feb;9(2):e88133.

53 Chmielewski M, Hahn O, Rappl G, Nowak M, Schmidt-Wolf IH, Hombach AA, et al. T cells that target carcinoembryonic antigen eradicate orthotopic pancreatic carcinomas without inducing autoimmune colitis in mice. Gastroenterology. 2012 Oct; 143(4): 1095107.e2.

54 Katari UL, Keirnan JM, Worth AC, Hodges SE, Leen AM, Fisher WE, et al. Engineered T cells for pancreatic cancer treatment. HPB (Oxford). 2011 Sep;13(9):643-50.

55 Abate-Daga D, Lagisetty KH, Tran E, Zheng $\mathrm{Z}$, Gattinoni L, Yu Z, et al. A novel chimeric antigen receptor against prostate stem cell antigen mediates tumor destruction in a humanized mouse model of pancreatic cancer. Hum Gene Ther. 2014 Dec;25(12):1003-12.

56 Maliar A, Servais C, Waks T, Chmielewski M, Lavy R, Altevogt P, et al. Redirected T cells that target pancreatic adenocarcinoma antigens eliminate tumors and metastases in mice. Gastroenterology. 2012 Nov; 143(5): 1375-1384.e5.
57 Posey AD Jr, Schwab RD, Boesteanu AC, Steentoft C, Mandel U, Engels B, et al. Engineered CAR T Cells Targeting the Cancer-Associated Tn-Glycoform of the Membrane Mucin MUC1 Control Adenocarcinoma. Immunity. 2016 Jun;44(6):1444-54.

58 Bailey P, Chang DK, Forget MA, Lucas FA, Alvarez HA, Haymaker C, et al. Exploiting the neoantigen landscape for immunotherapy of pancreatic ductal adenocarcinoma. Sci Rep. 2016 Oct;6(1):35848.

59 Yamazoe S, Tanaka H, Iwauchi T, Yoshii M, Ito $\mathrm{G}$, Amano R, et al. Identification of HLA$A^{*} 0201$ - and $A^{*} 2402-r e s t r i c t e d ~ e p i t o p e s$ of mucin 5AC expressed in advanced pancreatic cancer. Pancreas. 2011 Aug;40(6):896-904.

60 Inami K, Kajino K, Abe M, Hagiwara Y, Maeda M, Suyama M, et al. Secretion of N-ERC/ mesothelin and expression of C-ERC/mesothelin in human pancreatic ductal carcinoma. Oncol Rep. 2008 Dec;20(6):1375-80.

61 Yu L, Feng M, Kim H, Phung Y, Kleiner DE, Gores GJ, et al. Mesothelin as a potential therapeutic target in human cholangiocarcinoma. J Cancer. 2010 Oct;1:141-9.

62 Okada T, Noji S, Goto Y, Iwata T, Fujita T, Okada $\mathrm{T}$, et al. Immune responses to DNA mismatch repair enzymes $\mathrm{hMSH} 2$ and hPMS1 in patients with pancreatic cancer, dermatomyositis and polymyositis. Int J Cancer. 2005 Oct;116(6):925-33.

63 Utsunomiya T, Inoue H, Tanaka F, Yamaguchi H, Ohta M, Okamoto M, et al. Expression of cancer-testis antigen (CTA) genes in intrahepatic cholangiocarcinoma. Ann Surg Oncol. 2004 Oct;11(10):934-40.

64 Yokomine K, Senju S, Nakatsura T, Irie A, Hayashida Y, Ikuta Y, et al. The forkhead box M1 transcription factor as a candidate of target for anti-cancer immunotherapy. Int J Cancer. 2010 May;126(9):2153-63.

65 Maki RG, Livingston PO, Lewis JJ, Janetzki S, Klimstra D, Desantis D, et al. A phase I pilot study of autologous heat shock protein vaccine HSPPC-96 in patients with resected pancreatic adenocarcinoma. Dig Dis Sci. 2007 Aug;52(8):1964-72.

66 Bardeesy N, Cheng KH, Berger JH, Chu GC, Pahler J, Olson P, et al. Smad4 is dispensable for normal pancreas development yet critical in progression and tumor biology of pancreas cancer. Genes Dev. 2006 Nov;20(22):3130-46.

67 Gedde-Dahl T 3rd, Eriksen JA, Thorsby E, Gaudernack G. T-cell responses against products of oncogenes: generation and characterization of human T-cell clones specific for $\mathrm{p} 21$ ras-derived synthetic peptides. Hum Immunol. 1992 Apr;33(4):266-74.

68 Fossum B, Gedde-Dahl T 3rd, Hansen T, Eriksen JA, Thorsby E, Gaudernack G. Overlapping epitopes encompassing a point mutation (12 Gly- [\{GT\}]Arg) in p21 ras can be recognized by HLA-DR, -DP and -DQ restricted T cells. Eur J Immunol. 1993 Oct;23(10):268791.

69 Abrams SI, Khleif SN, Bergmann-Leitner ES Kantor JA, Chung Y, Hamilton JM, et al. Generation of stable CD4+ and CD8+ T cell lines from patients immunized with ras oncogenederived peptides reflecting codon 12 mutations. Cell Immunol. 1997 Dec;182(2):13751. 
70 Gjertsen MK, Bakka A, Breivik J, Saeterdal I, Solheim BG, Søreide O, et al. Vaccination with mutant ras peptides and induction of $\mathrm{T}$ cell responsiveness in pancreatic carcinoma patients carrying the corresponding RAS mutation. Lancet. 1995 Nov;346(8987):1399400.

71 Gjertsen MK, Buanes T, Rosseland AR, Bakka A, Gladhaug I, Søreide O, et al. Intradermal ras peptide vaccination with granulocytemacrophage colony-stimulating factor as adjuvant: clinical and immunological responses in patients with pancreatic adenocarcinoma. Int J Cancer. 2001 May;92(3):441-50.

72 Wedén S, Klemp M, Gladhaug IP, Møller M, Eriksen JA, Gaudernack G, et al. Long-term follow-up of patients with resected pancreatic cancer following vaccination against mutant K-ras. Int J Cancer. 2011 Mar;128(5):1120-8.

73 Abou-Alfa GK, Chapman PB, Feilchenfeldt J, Brennan MF, Capanu M, Gansukh B, et al. Targeting mutated K-ras in pancreatic adenocarcinoma using an adjuvant vaccine. Am J Clin Oncol. 2011 Jun;34(3):321-5.

74 Palmer DH, Dueland S, Valle JW, Aksnes AK. A phase I/II trial of TG01/GM-CSF and gemcitabine as adjuvant therapy for treating patients with resected RAS-mutant adenocarcinoma of the pancreas. J Clin Oncol. 2017;35 Suppl 15:4119.

75 Marshall JL, Hawkins MJ, Tsang KY, Richmond E, Pedicano JE, Zhu MZ, et al. Phase I study in cancer patients of a replication-defective avipox recombinant vaccine that expresses human carcinoembryonic antigen. J Clin Oncol. 1999 Jan;17(1):332-7.

76 Bilusic M, Heery CR, Arlen PM, Rauckhorst M, Apelian D, Tsang KY, et al. Phase I trial of a recombinant yeast-CEA vaccine (GI-6207) in adults with metastatic CEA-expressing carcinoma. Cancer Immunol Immunother. 2014 Mar;63(3):225-34

77 https://www.fdanews.com/articles/87938therion-reports-results-of-panvac-vf-trial, http://www.lifesciencesworld.com/news/ view/7586; 6 Jan 2019.

78 Brett BT, Smith SC, Bouvier CV, Michaeli D, Hochhauser D, Davidson BR, et al. Phase II study of anti-gastrin-17 antibodies, raised to G17DT, in advanced pancreatic cancer. J Clin Oncol. 2002 Oct;20(20):4225-31.

79 Gilliam AD, Broome P, Topuzov EG, Garin AM, Pulay I, Humphreys J, et al. An international multicenter randomized controlled trial of G17DT in patients with pancreatic cancer. Pancreas. 2012 Apr;41(3):374-9.

80 Shapiro J, Marshall J, Karasek P, Figer A, Oettle $\mathrm{H}$, Couture F, et al. G17DT+gemcitabine [Gem] versus placebo+Gem in untreated subjects with locally advanced, recurrent, or metastatic adenocarcinoma of the pancreas: results of a randomized, double-blind, multinational, multicenter study. J Clin Oncol. 2005; 23 Suppl 16:LBA4012.

81 Suehara N, Mizumoto K, Muta T, Tominaga Y, Shimura H, Kitajima S, et al. Telomerase elevation in pancreatic ductal carcinoma compared to nonmalignant pathological states. Clin Cancer Res. 1997 Jun;3(6):993-8.
82 Counter CM, Meyerson M, Eaton EN, Ellisen LW, Caddle SD, Haber DA, et al. Telomerase activity is restored in human cells by ectopic expression of hTERT (hEST2), the catalytic subunit of telomerase. Oncogene. 1998 Mar; 16(9):1217-22.

83 Buanes T, Maurel J, Liauw W, et al. A randomized phase III study of gemcitabine $(\mathrm{G})$ versus GV1001 in sequential combination with $\mathrm{G}$ in patients with unresectable and metastatic pancreatic cancer (PC). J Clin Oncol. 2009;27:4601.

84 Sahraei M, Roy LD, Curry JM, Teresa TL, Nath S, Besmer D, et al. MUC1 regulates PDGFA expression during pancreatic cancer progression. Oncogene. 2012 Nov;31(47): 4935-45.

85 Behrens ME, Grandgenett PM, Bailey JM, Singh PK, Yi CH, Yu F, et al. The reactive tumor microenvironment: MUC1 signaling directly reprograms transcription of CTGF. Oncogene. 2010 Oct;29(42):5667-77.

86 Hinoda Y, Ikematsu Y, Horinochi M, Sato S, Yamamoto K, Nakano T, et al. Increased expression of MUC1 in advanced pancreatic cancer. J Gastroenterol. 2003;38(12):1162-6.

87 Mall AS, Tyler MG, Ho SB, Krige JE, Kahn D, Spearman W, et al. The expression of MUC mucin in cholangiocarcinoma. Pathol Res Pract. 2010 Dec;206(12):805-9.

88 Besmer DM, Curry JM, Roy LD, Tinder TL, Sahraei M, Schettini J, et al. Pancreatic ductal adenocarcinoma mice lacking mucin 1 have a profound defect in tumor growth and metastasis. Cancer Res. 2011 Jul;71(13):4432-42.

89 Nath S, Daneshvar K, Roy LD, Grover P, Kidiyoor A, Mosley L, et al. MUC1 induces drug resistance in pancreatic cancer cells via upregulation of multidrug resistance genes. Oncogenesis. 2013 Jun;2(6):e51.

90 Yamamoto K, Ueno T, Kawaoka T, Hazama S, Fukui M, Suehiro Y, et al. MUC1 peptide vaccination in patients with advanced pancreas or biliary tract cancer. Anticancer Res. 2005 Sep-Oct;25(5):3575-9.

91 Ramanathan RK, Lee KM, McKolanis J, Hitbold E, Schraut W, Moser AJ, et al. Phase I study of a MUC1 vaccine composed of different doses of MUC1 peptide with SB-AS2 adjuvant in resected and locally advanced pancreatic cancer. Cancer Immunol Immunother. 2005 Mar;54(3):254-64.

92 Aruga A, Takeshita N, Kotera Y, Okuyama R, Matsushita N, Ohta T, et al. Phase I clinical trial of multiple-peptide vaccination for patients with advanced biliary tract cancer. J Transl Med. 2014 Mar;12(1):61.

93 Aruga A, Takeshita N, Kotera Y, Okuyama R, Matsushita N, Ohta T, et al. Long-term Vaccination with Multiple Peptides Derived from Cancer-Testis Antigens Can Maintain a Specific T-cell Response and Achieve Disease Stability in Advanced Biliary Tract Cancer. Clin Cancer Res. 2013 Apr;19(8):2224-31.

94 Simons JW, Mikhak B, Chang JF, DeMarzo AM, Carducci MA, Lim M, et al. Induction of immunity to prostate cancer antigens: results of a clinical trial of vaccination with irradiated autologous prostate tumor cells engineered to secrete granulocyte-macrophage colonystimulating factor using ex vivo gene transfer. Cancer Res. 1999 Oct;59(20):5160-8.
95 Soiffer R, Lynch T, Mihm M, Jung K, Rhuda $\mathrm{C}$, Schmollinger JC, et al. Vaccination with irradiated autologous melanoma cells engineered to secrete human granulocyte-macrophage colony-stimulating factor generates potent antitumor immunity in patients with metastatic melanoma. Proc Natl Acad Sci USA. 1998 Oct;95(22):13141-6.

96 Cox AL, Skipper J, Chen Y, Henderson RA, Darrow TL, Shabanowitz J, et al. Identification of a peptide recognized by five melanoma-specific human cytotoxic $\mathrm{T}$ cell lines. Science. 1994 Apr;264(5159):716-9.

97 Kawakami Y, Eliyahu S, Delgado CH, Robbins PF, Rivoltini L, Topalian SL, et al. Cloning of the gene coding for a shared human melanoma antigen recognized by autologous T cells infiltrating into tumor. Proc Natl Acad Sci USA. 1994 Apr;91(9):3515-9.

98 Greten TF, Jaffee EM. Cancer vaccines. J Clin Oncol. 1999 Mar;17(3):1047-60.

99 Dranoff G, Jaffee E, Lazenby A, Golumbek $\mathrm{P}$, Levitsky $\mathrm{H}$, Brose $\mathrm{K}$, et al. Vaccination with irradiated tumor cells engineered to secrete murine granulocyte-macrophage colony-stimulating factor stimulates potent, specific, and long-lasting anti-tumor immunity. Proc Natl Acad Sci USA. 1993 Apr;90(8): 3539-43.

100 Fearon ER, Itaya T, Hunt B, Vogelstein B, Frost $\mathrm{P}$. Induction in a murine tumor of immunogenic tumor variants by transfection with a foreign gene. Cancer Res. 1988 Jun; 48(11):2975-80.

101 Shirahama T, Muroya D, Matsueda S, Yamada A, Shichijo S, Naito M, et al. A randomized phase II trial of personalized peptide vaccine with low dose cyclophosphamide in biliary tract cancer. Cancer Sci. 2017 May;108(5):838-45.

102 Le DT, Ko AH, Wainberg ZA, Picozzi VJ, Kindler HL, Wang-Gillam A, et al. Results from a phase $2 b$, randomized, multicenter study of GVAX pancreas and CRS-207 compared to chemotherapy in adults with previously-treated metastatic pancreatic adenocarcinoma (ECLIPSE Study). J Clin Oncol. 2017;35 Suppl 4:345.

103 Lutz E, Yeo CJ, Lillemoe KD, Biedrzycki B, Kobrin B, Herman J, et al. A lethally irradiated allogeneic granulocyte-macrophage colony stimulating factor-secreting tumor vaccine for pancreatic adenocarcinoma. A Phase II trial of safety, efficacy, and immune activation. Ann Surg. 2011 Feb;253(2):32835.

104 Gorelik E, Duty L, Anaraki F, Galili U. Alterations of cell surface carbohydrates and inhibition of metastatic property of murine melanomas by alpha 1,3 galactosyltransferase gene transfection. Cancer Res. 1995 Sep; 55(18):4168-73.

105 Rossi GR, Mautino MR, Unfer RC, Seregina TM, Vahanian N, Link CJ. Effective treatment of preexisting melanoma with whole cell vaccines expressing alpha( 1,3$)$-galactosyl epitopes. Cancer Res. 2005 Nov;65(22): 10555-61.

106 https://www.onclive.com/web-exclusives/ pancreatic-cancer-vaccine-falls-short-inphase-iii-trial; 6 Jan 2019. 
107 Mildner A, Jung S. Development and function of dendritic cell subsets. Immunity. 2014 May;40(5):642-56.

108 Nestle FO, Alijagic S, Gilliet M, Sun Y, Grabbe S, Dummer R, et al. Vaccination of melanoma patients with peptide- or tumor lysate-pulsed dendritic cells. Nat Med. 1998 Mar;4(3):328-32.

109 Koido S, Homma S, Okamoto M, Takakura K, Mori M, Yoshizaki S, et al. Treatment with chemotherapy and dendritic cells pulsed with multiple Wilms' tumor 1 (WT1)-specific MHC class I/II-restricted epitopes for pancreatic cancer. Clin Cancer Res. 2014 Aug;20(16):4228-39.
110 Kaida M, Morita-Hoshi Y, Soeda A, Wakeda T, Yamaki Y, Kojima Y, et al. Phase 1 trial of Wilms tumor 1 (WT1) peptide vaccine and gemcitabine combination therapy in patients with advanced pancreatic or biliary tract cancer. J Immunother. 2011 Jan;34(1): 92-9.

111 Lepisto AJ, Moser AJ, Zeh H, Lee K, Bartlett D, McKolanis JR, et al. A phase I/II study of a MUC1 peptide pulsed autologous dendritic cell vaccine as adjuvant therapy in patients with resected pancreatic and biliary tumors. Cancer Ther. 2008;6 B:955-64.

112 Pecher G, Häring A, Kaiser L, Thiel E. Mucin gene (MUC1) transfected dendritic cells as vaccine: results of a phase I/II clinical trial. Cancer Immunol Immunother. 2002 Dec; 51(11-12):669-73.
113 Kobayashi M, Sakabe T, Abe H, Tanii M, Takahashi H, Chiba A, et al.; DC-vaccine study group at the Japan Society of Innovative Cell Therapy (J-SICT). Dendritic cellbased immunotherapy targeting synthesized peptides for advanced biliary tract cancer. J Gastrointest Surg. 2013 Sep;17(9):1609-17.

114 Gao HL, Liu L, Qi ZH, Xu HX, Wang WQ, $\mathrm{Wu}$ CT, et al. The clinicopathological and prognostic significance of PD-L1 expression in pancreatic cancer: A meta-analysis. Hepatobiliary Pancreat Dis Int. 2018 Apr;17(2): 95-100. 